\title{
INSTITUIÇÕES E ESFERA PÚBLICA CISTERNAS ESCOLARES NO SEMIÁRIDO
}

Thor Saad Ribeiro

\section{INTRODUÇÃO}

Recentemente, o paradigma de desenvolvimento do Semiárido Nordestino tem se transformado. Antes baseado em uma lógica de combate à seca, agora se trata de criar formas de convivência com a seca. Isso significa substituir ações paternalistas, assistencialistas e emergenciais por soluções estruturantes, que apontam para uma efetiva superação das precariedades de bem-estar social e de produção econômica que ainda marcam a região (SILVA, 2006; FERREIRA, 2009).

A atuação da Articulação do Semiárido (ASA) e de outras organizações não governamentais tem sido o grande destaque dessa mudança, influenciando e implementando políticas públicas, difundindo novas práticas e conhecimentos e apoiando a mobilização social necessária para o embate com as formas de desenvolvimento arcaicas ou excludentes.

Essa atuação é fortemente marcada pelo questionamento das categorias e regimes de propriedade e governança predominantes na região. Trata-se de um movimento por vezes contestatório, como por exemplo no caso da luta contra a concentração fundiária, creditícia, de recursos hídricos, etc.; e por vezes criativo, inovando e adaptando, buscando substituir ou complementar estruturas de mercado ou estatais por modelos de governança comum.

Dentre as práticas de convivência com a seca, destacam-se as tecnologias sociais. Trata-se de "um conjunto de técnicas, metodologias transformadoras, desenvolvidas e/ ou aplicadas na interação com a população e apropriadas por ela, que representam 
soluções para a inclusão social ou melhorias das condições de vida" (ITS, 2004:130, apud RODRIGUES; BARBIERI, 2008). No Seminário, o exemplo mais emblemático são as cisternas de captação de água da chuva. Há uma notável tradição de construção de cisternas para consumo e produção familiares. $\mathrm{O}$ novo horizonte de intervenção são as cisternas comunitárias, como as cisternas escolares, um equipamento capaz de suprir as necessidades de água de escolas rurais com acesso precário ao recurso.

Consoante com os princípios das tecnologias sociais, trata-se de um equipamento de relativo baixo custo, que deve ser apoiado e mantido pela comunidade, e com grandes benefícios para as populações afetadas. Garantir água de qualidade nas escolas rurais traz vantagens do ponto de vista da saúde e da segurança alimentar, além de impactar indiretamente na qualidade da educação. Mais ainda, a escola é um espaço privilegiado de aprendizagem e transformação social, possibilitando a difusão dos princípios da convivência com o Semiárido e do desenvolvimento sustentável e reunindo a comunidade escolar em torno de um projeto de educação contextualizada. Como veremos, o caráter comunitário dessa tecnologia também busca impactar no perfil da governança local.

A despeito do grande potencial desse tipo de intervenção, a adesão de prefeituras, comunidades, professores e alunos a essa nova tecnologia não é garantida. Ao contrário das cisternas familiares, constatou-se que nesse caso, há uma maior dificuldade de envolver as partes no seu cuidado e uso corretos, o que pode levar ao abandono, subutilização ou contaminação da água. No presente artigo, buscaremos levantar as causas das dificuldades de apropriação e manutenção das cisternas escolares. Para tanto, analisaremos essa tecnologia social sob o prisma da governança institucional, buscando elucidar como os incentivos, percepçôes e valores dos atores concorrem para seu êxito ou fracasso.

\section{METODOLOGIA}

Para estabelecer os elementos e causas envolvidos no processo de implementação das cisternas escolares, foi realizada uma pesquisa exploratória, de tipo qualitativo. Em primeiro lugar, foi realizado um levantamento da literatura acadêmica concernente à ASA e ao programa de cisternas. Em seguida, foram realizadas entrevistas não estruturadas com os gestores do governo federal responsáveis pelo programa, e membros da $\mathrm{ASA}^{78}$.

As entrevistas foram realizadas no segundo semestre de 2015, e abrangeram dois gestores do MDS e dois coordenadores da Articulação do Semiárido envolvidos diretamente com a promoção de cisternas comunitárias. 
Foi também feita uma análise de fontes secundárias, como jornais e boletins informativos. Por fim, foi fundamental a consulta a uma avaliação realizada pelo Instituto Brasileiro de Desenvolvimento e Sustentabilidade - IABS, parte do processo de cooperação BRA-007-B (no prelo), baseada em um intenso trabalho de campo e entrevistas com gestores, representantes de entidades e financiadores.

\section{CISTERNAS ESCOLARES E A EDUCAÇÃO NO CAMPO}

A cisterna escolar teve sua origem junto ao Programa um Milhão de Cisternas (P1MC), ${ }^{79}$ em 2003. No entanto, durante a década de 2000, a construção de cisternas de consumo familiares (cisternas de primeira água) teve absoluta precedência sobre as cisternas de produção (cisternas de segunda água) e cisternas comunitárias (cisternas de terceira água, ou água do conhecimento), dado que o acesso à água de consumo doméstico foi considerado um problema mais urgente. Com isso, somente ao final da década algumas entidades da ASA, com destaque para o Movimento de Organização Comunitária-MOC, da Bahia, começaram a tomar a frente na construção desses equipamentos. Após um segundo projeto piloto em Alagoas, a construção de cisternas ganhou novo impulso a partir da regulamentação pelo Ministério de Desenvolvimento Social e Combate à Fome - MDS (BRASIL, 2014) e projetos com financiamento internacional. Em 2015, foram iniciadas 2.500 cisternas escolares no Semiárido, a partir de um mapeamento de escolas rurais com mais de 50 alunos, consideradas de acesso precário à água pelo Censo Escolar. Seu custo gira em torno de R \$13.000, a depender do estado. O financiamento da construção é feito pelo Governo Federal e a execução cabe às entidades parceiras, em geral membros da ASA.

É fundamental notar que a cisterna não se resume a um equipamento de infraestrutura. Essa tecnologia social foca também o processo e a deliberação envolvidos na sua criação e implementação, ou seja, tem um importante vetor pedagógico e político. No caso dos programas de cisternas da ASA, isso se traduz na construção do equipamento, oficinas de capacitação para o uso adequado da água, a difusão de conhecimentos sobre técnicas de produção a partir dessa água e a sensibilização a respeito do meio ambiente e do meio social do Semiárido.

79 O P1MC foi o principal programa de construção de cisternas no Semiárido, fruto da articulação entre o Governo Federal e a ASA. Iniciado em 2003 e ainda em atividade, o P1MC é considerado uma iniciativa bem sucedida de acesso a recursos hídricos, tendo levado à construção de centenas de milhares de cisternas familiares e de produção. 
•• Série Direito, Economia e Sociedade

Especificamente para as cisternas escolares, a ASA propõe um trabalho de envolvimento da comunidade escolar, através de oficinas de mobilização. Antes da construção efetiva da cisterna, deve-se realizar um encontro de mobilização territorial, abrangendo representantes de até 50 escolas. Em seguida é formada uma comissão municipal em cada cidade, abrangendo até 10 escolas. Por fim, segue-se uma reunião com a comunidade escolar de cada unidade educacional, e a capacitação de pelo menos dois representantes da escola para a gestão da água e práticas de convivência. Ao fim desse processo, é construída a cisterna, de 52 mil litros, que em condiçôes normais de uso é capaz de atender as necessidades básicas de consumo e alimentação durante um período de estiagem típico.

Para além das necessidades imediatas de água e alimentação adequada, a cisterna escolar possibilita práticas de convivência. Essa expressão designa iniciativas pedagógicas, que objetivam subverter a identidade negativa do Semiárido, associada à a carência e escassez, e revalorá-la como pregnante de possibilidades e riquezas por descobrir (MARINHO, 2006). A água da cisterna possibilita, por exemplo, a criação de uma horta, na qual se desenvolvem práticas de educação contextualizada, e que acaba funcionando como um pequeno laboratório na qual diferentes espécies, culturas e animais podem ser objeto de exploração pelos alunos e professores, ao mesmo tempo em que sua produção suplementa a merenda escolar.

Uma terceira dimensão importante da intervenção é a de incentivar a participação da comunidade escolar no processo educativo. A educação é um serviço coproduzido, e não uma mera oferta do Estado (OSTROM, 1993). Nesse sentido, pesquisas têm apontado que a participação das famílias no dia a dia escolar é importante para melhorar o desempenho do processo educacional (Unicef, 2012). Isso ocorre por dois canais: o maior envolvimento no cotidiano de tarefas e disciplinas pelos pais influencia na disposição e valorização da educação pelos filhos; por outro lado, esse envolvimento induz a valorização e participação na educação pela comunidade escolar, que passa a exercer pressão e demandar accountability por parte de gestores, diretores e professores. O envolvimento também garante um processo continuado de aprendizado e práticas de convivência entre os adultos como pais, professores e merendeiras.

Essas ações precisam ser entendidas à luz das condições da educação no campo no contexto brasileiro. Os índices educacionais no campo são significativamente 
piores que nas zonas urbanas. Somente 39,1\% dos adolescentes entre 15 e 17 anos das zonas rurais estão no ensino médio, contra 57,3\% nas áreas metropolitanas. No ensino fundamental rural do Nordeste, a distorção idade-série encontra-se em $37 \%$, enquanto a taxa para o Nordeste urbano é de 30\%. Esses resultados são decorrentes de fatores conhecidos: professores de pior formação, classes multisseriadas, falta de material escolar, educação descontextualizada e infraestrutura precária (Unicef, 2012). O acesso precário à água nessas escolas implica no fechamento ocasional, dificulta a higiene básica, piora ou impossibilita a merenda escolar e facilita a transmissão de doenças de veiculação hídrica ou alimentar.

Esse cenário tem gerado uma solução perniciosa: a nucleação de escolas, com o atendimento de crianças e adolescentes do campo em escolas da cidade por meio do transporte escolar. De fato, um estudo da Unicef (2012) afirma que 35,82\% dos alunos que habitam em região rural nos estados do Semiárido vão à escola urbana, por meio de transporte escolar. Nos anos finais do Ensino Fundamental, esse percentual alcança 62,08\%, e no Ensino Médio, 92,20\%. Essa prática é justificada pelo baixo desempenho e alto custo das escolas rurais, mas é considerada desastrosa pelos movimentos sociais do campo, pois impõe uma educação descontextualizada, afasta o jovem do campo de suas raízes e promove o êxodo rural. Perde-se a oportunidade de que a educação seja uma forma de se transformar o meio no Semiárido, ao se passar a mensagem de que não há futuro no campo, e de que este é um espaço arcaico e estéril (Unicef, 2012).

Obviamente, a cisterna escolar não é uma panaceia capaz de reverter o legado histórico de negligência que resultou nesse cenário. Mas ela pode representar um importante vetor de mudança, ajudando a sanar a necessidade imediata de acesso à água de qualidade, ao mesmo tempo mantém as escolas no campo, cria melhores condições para a educação e fomenta a gestão comunitária de recursos comuns. No entanto, apesar desses grandes benefícios aparentes, os primeiros pilotos apontam que nem sempre a cisterna escolar é capaz de realizar seu potencial. Avaliações realizadas pela Embrapa e pelo IABS revelam que a manutenção, o uso e o envolvimento em torno das cisternas sofrem ocasionalmente de graves deficiências. Essa situação revela um problema de governança de um recurso de uso comum, que é também um equipamento de infraestrutura rural. No resto do artigo, buscaremos entender as razões para essa falha de governança a partir de um olhar sobre o desenho institucional do programa. 


\section{CISTERNAS ESCOLARES: UMA ANÁLISE INSTITUCIONAL}

\subsection{Desenvolvimento, infraestrutura rural e instituições}

As cisternas escolares, assim como as próprias escolas fazem parte de um projeto de desenvolvimento, cujo marco normativo atual é o desenvolvimento sustentável. Se no passado o desenvolvimento era entendido como o mero acúmulo de capital físico e o enriquecimento de nações e populações, atualmente compreende-se o conceito como o aumento do bem estar humano que não ameaça os sistemas biogeofísicos ou culturais (YOUNG, 2010). Pela ótica institucional, desenvolvimento decorre não só do incremento dos meios físicos de produção e consumo, mas depende fundamentalmente dos contextos sociais e ambientais.

$\mathrm{Na}$ análise dos processos de desenvolvimento, há um crescente consenso de que o principal fator a ser considerado são as instituiçôes, ou seja, o conjunto de regras, formais e informais que regem as relaçôes entre membros das organizações que estruturam a vida social (PORTES, 2010) ${ }^{80}$ incluídos aqui os incentivos, as formas de pactuação e de organização. $\mathrm{O}$ enfoque institucional é particularmente útil na análise de iniciativas de desenvolvimento como a implantação de infraestrutura, revelando aspectos como adoção, viabilidade, impacto e aceitação. Trata-se aqui de compreender os dilemas de ação coletiva, de formação de contratos e de realização de expectativas que se apresentam a usuários, executores, financiadores e interessados. No caso da infraestrutura rural, alguns desses dilemas podem ser amplificados pela peculiaridade territorial. Como afirma Ostrom (1993, p. 30): "Rural infrastructure facilities are frequently used jointly by many individuals, whose preferences, stakes and use patterns vary dramatically". Dessa forma, o sucesso da cisterna escolar depende dos incentivos que se apresentam aos atores envolvidos: o Governo Federal, como financiador, os governos locais, como gestores das escolas, as entidades executoras, comunidades, pais e alunos.

80 Instituição é um termo sociologico altamente equívoco, no entanto muito útil como conceito heurístico desde que bem definido. Nesta análise, seguimos a definição pragmática de Portes (2006), para o qual as instituições são as dinâmicas culturais implícitas nas organizações, ou seja, a parte visível da esfera da cultura, correlata da esfera da estrutura social. Essa definição permite evitar certa tradição econômica simplista de creditar às instituições qualquer restrição externa sobre os agentes, e amplia o escopo de análise da vida social não só para as "regras do jogo" explícitas, mas também para os valores e relações de poder implícitos nesses jogos. O uso de um enfoque institucionalista é particularmente relevante em situações onde não se tem uma governança de mercado/propriedade privada individual, mas sim formas públicas, cooperativas ou solidárias, dado que nestas a a viabilidade e impacto não são reveladas contabilmente pelo lucro, e dependem de formas de motivação e interação bastante diferentes. 
A autora demonstra também que o alinhamento desses interesses e ações pressupõe regimes de propriedade e governança que se adequem ao contexto local e histórico, pois frequentemente há uma variação grande de regimes de usufruto, propriedade e mando a depender do espaço social. A cisterna escolar é formalmente (de jure) um equipamento público, parte de uma escola estatal, sob autoridade municipal. No entanto, justamente seu potencial está em ampliar a participação e o sentimento de ownership comunitário de si e da própria escola na prática (de facto).

Ostrom (1993) afirma que o sucesso de instâncias de infraestrutura rural de pequena escala depende de que os beneficiários:

- Estejam conscientes dos benefícios potenciais.

- Reconheçam que esses benefícios dependem da manutenção do equipamento.

- Façam um compromisso firme para manter o equipamento ao longo do tempo.

- Tenham as capacidades organizacionais para manter o equipamento.

- Não esperem receber recursos para manter o equipamento, caso não providenciem a manutenção por si mesmos.

Três "camadas" sobressaem nesses fatores. A primeira está ligada ao contexto físico do equipamento, seus custos e benefícios diretos. A segunda diz respeito às percepções dos atores, que podem ou não interpretar os custos e benefícios de forma correta. A terceira, por sua vez, se refere aos valores e normas profundos que estão implícitos nas percepções.

\subsection{Os problemas}

A avaliação realizada pela Embrapa sobre 23 projetos piloto de cisternas escolares revelou fragilidades na manutenção e uso dos equipamentos. Apenas 5 das cisternas de produção apresentaram resultado favorável em relação a todo o ciclo de cisterna-horta-alimentação. Além disso, a maior parte das bombas encontrava-se inoperante, e foram achados casos de contaminação, rachaduras e cisternas ociosas. Particularmente grave foi a constatação da presença de fezes de pássaros e morcegos nos telhados, que, se não lavadas, podem acarretar a transmissão de raiva e outras doenças (BRITO et al., 2012).

$\mathrm{Na}$ mesma avaliação, foi percebido que quando ocorrem, essas falhas estão associadas a uma desresponsabilização geral - da comunidade, dos professores e do 


\section{•• Série Direito, Economia e Sociedade}

poder público - pelas cisternas. Corroborando esse diagnóstico, a avaliação realizada pelo IABS (no prelo) aponta que foram verificados casos de desinteresse por parte de professores, de comunidades e do poder público, impactando diretamente na sua sustentabilidade e performance.

\subsection{O contexto}

O elemento primordial para avaliar a sustentabilidade e performance de um equipamento é seu custo-benefício (OSTROM, 1993). Como afirmamos, a cisterna escolar em plena operação pode representar um ganho expressivo na oferta de educação, alimentação, promoção da saúde, e também de formas de riqueza intangíveis como o capital social e a difusão de práticas de convivência com a seca.

Por outro lado, os custos também são de diversos tipos. A cisterna exige uma manutenção constante, com a limpeza das calhas e telhados, o cuidado e reparo de eventuais rachaduras, o monitoramento da água (especialmente quando há recarga por caminhões-pipa) e a manutenção das hortas. Há também os chamados custos de transação, contratualização e participação, ou seja, o tempo e esforço gasto na pactuação e divisão de tarefas e monitoramento dos compromissos e sanção dos descumpridores.

No caso das cisternas escolares, percebe-se que os custos envolvidos são baixos. As tarefas de manutenção, se divididas, envolvem um baixo custo financeiro ou de tempo, considerando a baixa complexidade e custo total do equipamento. Os processos de limpeza são simples, exigem uma capacitação rápida, sendo que estas são financiadas pelo Governo Federal e ministradas pela entidade executora antes mesmo da construção da cisterna. As partes e peças utilizadas são baratas e de simples acesso, e a manutenção da estrutura pode ser realizada por um pedreiro treinado. Considerando que escolas beneficiárias têm no mínimo 50 alunos, a repartição desses custos entre a comunidade e o poder público local não representa um desafio de grande monta. Por fim, os grupos envolvidos são relativamente pequenos, não representando um desafio intransponível a sua articulação. A subutilização ou abandono da cisterna envolve, portanto, um alto custo de oportunidade.

\subsection{As percepções}

O mero fato de que um benefício é acessível a um baixo custo não basta para que ele seja de fato oferecido. É preciso que ele seja percebido como valioso. Não 
dispomos de informações diretas sobre quanto às comunidades afetadas valorizam diretamente cada um desses benefícios, mas podemos aqui fazer algumas suposições e utilizar de proxies.

No caso dos benefícios educacionais, é plausível supor que os altos retornos do estudo não sejam compreendidos por pais e alunos, um fenômeno comum em países em desenvolvimento (BHANERJEE; DUFLO, 2011). Mesmo que restritos à dimensão econômica, Barbosa e Pessoa (2008) estimam em 10\% taxa de retorno da educação, ou seja, o acréscimo de renda que o indivíduo auferirá quando adulto para cada ano estudado a mais. Trata-se de um retorno extremamente alto. Ainda assim, persiste uma alta taxa de trabalho infantil e alta carga de trabalhos domésticos de crianças e adolescentes, que concorrem diretamente com o estudo e levam ao baixo desempenho e evasão (Unicef, 2009). Este é um cenário que vem mudando rapidamente, com a valorização da educação ganhando terreno e o trabalho infantil diminuindo, mas é possível afirmar que se verifica ainda uma subestimação dos benefícios da educação, com impactos adversos nos incentivos para participar da vida escolar e na manutenção da infraestrutura escolar.

Já em relação aos benefícios de saúde, a atuação de agentes de saúde e a disseminação das cisternas familiares foram vetores importantes para a difusão dos conhecimentos ligados a importância do consumo de água própria e do preparo adequado de alimentos. No entanto, ainda permanecem altas os níveis de doenças de transmissão hídrica e alimentar (PORTELA; LEITE; PEREIRA, 2013), o que indica em parte uma falta de conhecimento dos meios de prevenção. Por isso, é plausível supor que a cisterna escolar poderia ser mais valorizada caso seus benefícios sobre a saúde fossem mais conhecidos.

Nesse sentido, acompanham a construção da cisterna as rodadas de participação e capacitação, que também têm como objetivo informar acerca desses benefícios, especialmente aqueles ligados à saúde. Para o IABS (no prelo), essas capacitações são determinantes no sentido de esclarecer sobre os ganhos para a comunidade.

\subsection{Os valores}

Além de custos, benefícios e percepções, é importante considerar os valores das populações rurais do Semiárido, e de que maneira eles afetam as percepções e ações dos atores. Como os valores são uma camada mais profunda e perene da vida social, faz-se necessária uma pequena digressão histórica. 
Os vieses de percepção não são uma simples miopia, nem podem ser inteiramente responsabilizados pelo desempenho institucional. As instituições, afinal, estão inseridas no campo da cultura, e são somente o desdobramento mais visível da dinâmica entre valores, normas, papéis e repertórios de habilidades. A forma como os incentivos são percebidos e valorados depende fundamentalmente desses padrões de normalidade, desejabilidade e impossibilidade que são transmitidos na socialização dos indivíduos (PORTES, 2006).

Em um contexto republicano, espera-se que o espaço público seja considerado pertencente a todos, sendo também responsabilidade geral participar e influir no destino da coletividade, e também zelar pelos equipamentos e serviços que compõem esse espaço. Trata-se do que Putnam (1993) denominou civismo. As origens deste estariam em uma sociedade com alto grau de capital social, capaz de impor aos governantes um comportamento responsivo e transparente (accountable).

Esse não foi o roteiro histórico do Semiárido nordestino. Retardatário social e econômico desde o século XIX, a região tardou a modernizar-se (FURTADO, 1976). O legado desse processo é a manutenção de um Estado caracterizado pela extração, ou seja, o Estado que regula a produção unicamente em nome de uma elite, sem a participação de outros grupos ou desenvolvimento da coletividade. Ainda que a região tenha conhecido um surto de crescimento e mudança a partir de intervençôes desenvolvimentistas no século XX, esta não superou, mas consolidou o padrão de ação estatal fundado no paternalismo-patrimonialismo-autoritarismo (BURZSTYN, 1985). Nesse molde, o Estado age de forma unilateral de maneira a permitir o acúmulo (de terras, crédito, água e outros recursos) para uma elite, ao mesmo tempo em que se legitima e contém a pressão social por meio dos favores e do assistencialismo e coíbe a formação de grupos e associações reivindicatórias.

Obviamente, essa narrativa estilizada já não corresponde à realidade do Semiárido. Entretanto, esse padrão de atuação deixou como marca uma esfera pública atrofiada. Por um largo período, não houve incentivos à participação social, ou o desenvolvimento de uma lógica republicana pela qual equipamentos e políticas públicas pertencem em última instância ao povo, sendo os agentes públicos meros delegados precários dessa titularidade. Pelo contrário, prevaleceu, e continua em partes, uma lógica de favores, pela qual os serviços públicos são benesses, a serem devolvidos na forma de voto, apoio ou silêncio.

Não surpreende, portanto, que um dos maiores entraves à performance das cisternas escolares é a ausência de apropriação (ownership) por parte da comunidade 
e do poder local (IABS, 2013; BRITO et al., 2012). No caso, é bastante presente a fala de que o que a cisterna e a escola pertencem ao poder público, e são de exclusiva responsabilidade deste. Essa atitude revela um padrão particular de interação das populações do Semiárido com o Estado. Como expressam Neves e Pereira (2013):

A articulação conjunta do poder público local e as comunidades mexe em relaçôes políticas personificadas que não contribuem com o bem-estar da população. A escola é, por vezes, percebida como um espaço do prefeito, e não um espaço público, o que leva a equívocos que dizem respeito aos deveres e direitos das comunidades e do poder público. As ações chegam à escola através de decisões externas às comunidades. Assim, estas se isentam de responsabilidades e também dos direitos para com a escola, já que compreendem o espaço como sendo do prefeito, logo, também é dele a responsabilidade com tudo o que diz respeito à instituiçãa. Essas questôes são ainda potencializadas em momentos de eleições municipais.

Essa desresponsabilização por vezes significa um triste desfecho para a coletividade, e não somente no caso das cisternas escolares. Outros equipamentos de fácil manutenção também são encontrados abandonados ou subutilizados na região, como é o caso dos dessalinizadores distribuídos pelo programa Água Boa. Uma avaliação externa (FUNDEPES, 2013) concluiu que, apesar dos óbvios benefícios de se obter água própria a partir da salobra, nem sempre os equipamentos eram geridos de forma adequada, e uma vez que apresentassem defeitos mínimos eram abandonados. Ao invés de uma reação de reivindicação ou de resolução, é comum que se reporte a resignação com a perda do dessalinizador.

\section{CONCLUSÃO}

As cisternas familiares possuem características que tornam sua governança transparente e direta em relação aos custos, benefícios e responsabilidades. Já as cisternas escolares representam um novo desafio nas práticas de convivência com a seca, pois apresentam um desafio de ação coletiva.

Características do contexto físico e social, percepçōes e vieses, e valores enraizados concorrem para essas dificuldades. No entanto, sugerimos preliminarmente aqui que são dois os principais entraves: a baixa valorização social da educação e um padrão de relação da sociedade com o Estado marcada por uma participação cívica historicamente tolhida. Ambos estão profundamente relacionados ao histórico de profundas desigualdades socioeconômicas da região e são entraves ao desenvolvimento sustentável, ainda que as estruturas arcaicas pareçam profundamente abaladas por mudanças recentes. 
Esse diagnóstico não comporta nenhum fatalismo a respeito dessa realidade. De fato, as múltiplas privações materiais, sociais e políticas se retroalimentam, convergindo para a manutenção de um estado de subdesenvolvimento. No entanto, as tecnologias sociais trazem consigo o potencial de mudança desse conjunto. Não se trata somente de trazer uma melhoria técnica, um bem inovador. Importa que esse incremento técnico esteja acompanhado de um processo para a melhoria institucional. No caso das cisternas escolares, o ciclo de participação, capacitação e deliberação diz respeito exatamente a esses pontos. É por meio deles que é possível transformar os elementos profundos do mundo da cultura, como os valores e as percepçôes. (PORTES, 2006). A governança do equipamento, isto é, os incentivos envolvidos em sua gestão, manutenção e uso estão inseridos (embedded) nesse caldo cultural. Como notam Neves e Pereira (2013):

Todavia, onde se conseguiu traçar acordos entre prefeituras, comunidade escolar e comunidade local, deixando claro suas próprias responsabilidades, bem como as de todos os parceiros, pode-se vivenciar experiências de como deve se dar a vida política, com o envolvimento de todas e todos.

Isso mostra que as percepções e valores considerados como arraigados e profundos, são passíveis de sofrer mudanças súbitas e radicais. Entretanto, a expectativa depositada no programa não se limita mesmo à provisão de água pura, alimentos, educação ambiental, participação escolar e os demais benefícios ligados diretamente à escola. Espera-se também que essa experiência de gestão comunitária e participativa transborde para outros empreendimentos e equipamentos, espaços e formas de convivência que apontam para novas formas de vida social e econômica, calcadas em formas bastante diversas da propriedade privada como tradicionalmente concebida e uma dinâmica de acumulação alheia ao bem público.

A cisterna escolar é, nas palavras de um entrevistado, um "laboratório e uma escola de cooperação e ação conjunta”. É também parte um vasto repertório de tecnologias e intervençôes da ASA, que inclui a produção cooperativa, a economia solidária, o crédito comunitário, bancos de sementes, entre outras. Esse repertório, visto em sua totalidade, aponta para um horizonte de desmercadorização de aspectos essenciais da vida, ao afastá-los do modelo único da propriedade privada; e de sua democratização, ao sujeitá-los a formas de gestão inclusivas e deliberativas.

O que a implementação das cisternas escolares revela é que a agenda desse repertório depende fundamentalmente do valor que se dá aos bens públicos e comunitários, e na robustez da esfera cívica. Revela também como se pode transformar e fortalecer essa esfera. Nesse ponto, buscamos demonstrar que o desenho da 
intervenção e os incentivos são críticos para a viabilidade, bem como a atenção ao contexto sócio-histórico.

\section{REFERÊNCIAS}

BARBOSA, F. H.; PESSOA, S. 2008. Retornos da educação no Brasil. In: Pesquisa e Planejamento Econômico, 38(1):97-125.

BHANERJEE, A.; DUFLO, E. Poor economics: a radical rethinking of the way to fight global poverty. New York. Public Affairs. 2011.

BRASIL, 2014. Instrução Operacional, 2, de 15 de abril de 2014.

BRITO, L. T. L.; AZEVEDO, S.G.; ARAÚJO, O. J. Escolas rurais produzem hortaliças e frutas utilizando água de chuva armazenada em cisterna: estudo de caso. In: Simpósio Brasileiro de Captação e Água da Chuva. Campina Grande, 2012.

BURZSTYN. M. O poder dos donos: planejamento e clientelismo no Nordeste. Petrópolis: Vozes, 1985.

FERREIRA, I. A. Água e política no sertão: desafios ao programa um milhão de cisternas - Universidade de Brasília, 2009.

FURTADO, C. Formação econômica do Brasil. 14. ed. São Paulo: Ed. Nacional, 1976.

NEVES, R.S., PEREIRA, C. M. Cisternas nas escolas: portas de entrada para uma educação contextualizada no semiárido. In: Estratégias de convivência com o semiárido 3. Brasília: Editora IABS, 2013.

OLSON, M. A lógica da ação coletiva. São Paulo, EDUSP, 1999.

OSTROM, E. Governing the commons: the evolution of institutions for collective action. New York: Cambridge University Press, 1990.

OSTROM, E; SCHROEDER, L.; WYNNE, S. Institutional Incentives and Sustainable Development: Infrastructure Policies in Perspective. Boulder: Westview.1993.

PORTELA, R.A., LEITE, V.D., PEREIRA, C. F. (2013). Comportamento das doenças diarréicas nas mudanças sazonais no Município de Campina Grande. Revista Brasileira de Geografia Médica e da Saúde, Hygeia 9-17, p. 116-128. 2013.

PORTES, A. Social capital: its origins and applications in modern sociology. In: Knowledge and Social Capital. Boston: Butterworth-Heinemann, 43-6. 2000.

PORTES, A. Instituciones y desarrollo: una revisión conceptual. Cuadernos de Economia, v. XXV, 45: 13-5, 2006.

PUTNAM, R. Comunidade e democracia: a experiência da Itália moderna. Rio de Janeiro: Fundação Getúlio Vargas, 1996. 


\section{•• Série Direito, Economia e Sociedade}

RODRIGUES, I., BARBIERI, J. C. A emergência da tecnologia social: revisitando o movimento da tecnologia apropriada como estratégia de desenvolvimento sustentável. Rev. Adm. Pública, dez. 2008, v. 42, 6, p. 1069-1094, 2008. ISSN 0034-7612.

SILVA, R. M. Entre o combate à seca e a convivência com o semi-árido: transições paradigmáticas e sustentabilidade do desenvolvimento, 298f., il. Tese (Doutorado em Desenvolvimento Sustentável) - Universidade de Brasília, Brasília, 2006.

Unicef. O enfrentamento da exclusão escolar no Brasil. Brasília, 2012. Disponível em: $<$ http://www.foradaescolanaopode.org.br/downloads/Livro_O_Enfrentamento_da_ Exclusao_Escolar_no_Brasil.pdf>.

YOUNG, O. Governance for sustainable development in a world of rising interdependencies. In DELMAS, M. A.; O. YOUNG, Governance for the environment: new perspectives. Cambridge University Press, Cambridge, New York, Melbourne, Cape Town, Madrid, Singapore, São Paulo, Delhi. Cap. 1. 2010. 